\title{
||||||||||||||||||||||||||||||||||||||||||||||||||||||||||||||||||.
}

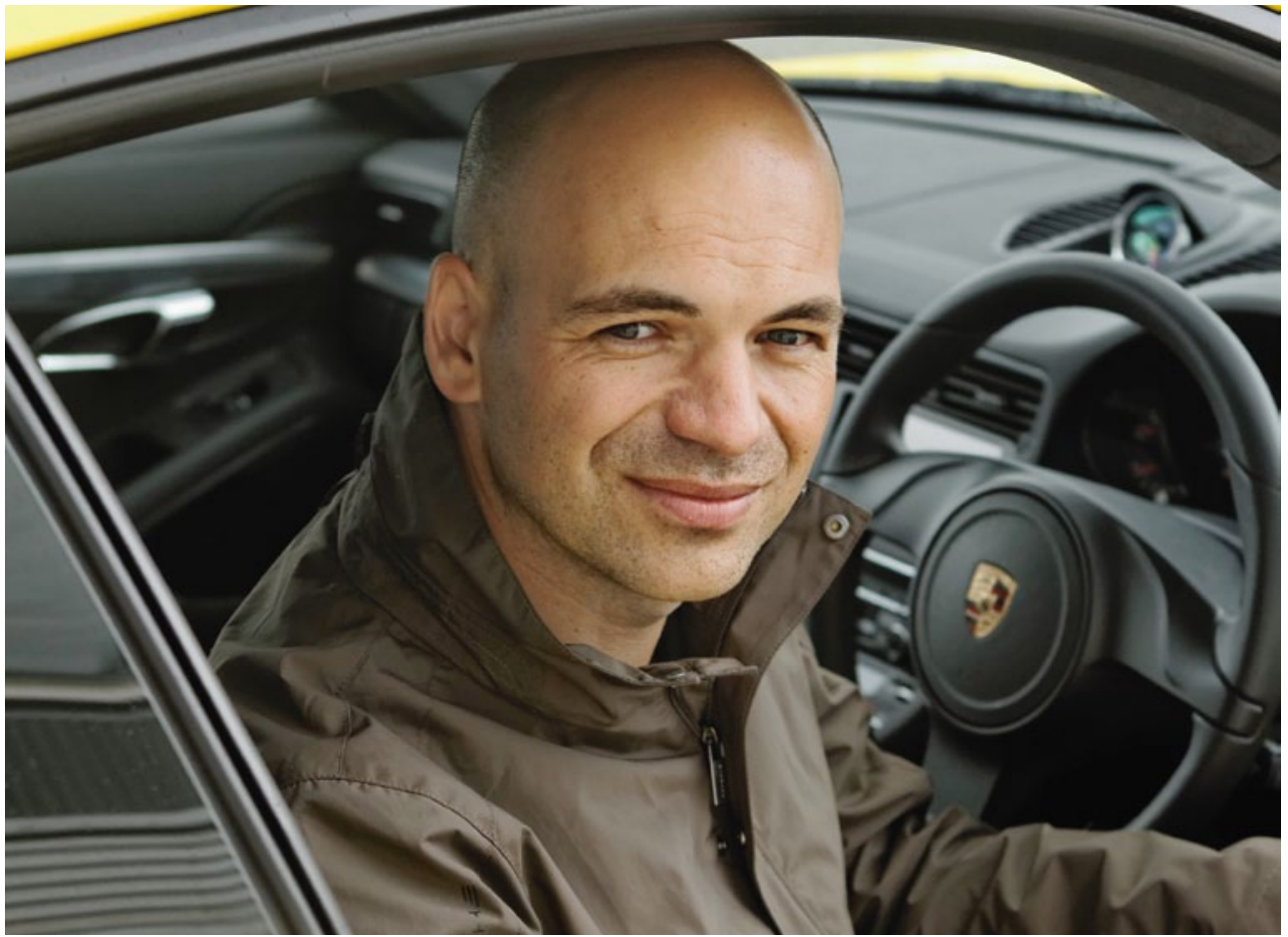

DR. MANFRED HARRER

Leiter Entwicklung Fahrdynamik und Performance, Dr. Ing. h. c. F. Porsche AG

\section{URMETER FÜR DIE SPORTWAGENWELT}

1963 erblickte der Porsche 911 das Licht der Welt - und gilt seither als Maßstab für sportlichen Fahrspaß bei gleichzeitig hoher Alltagstauglichkeit. Der 911er - das sind sieben Generationen Motorsporterfolg und 50 Jahre Perfektionierung eines einzigartigen Fahrzeugkonzepts für Straße und Rennstrecke.

Begonnen hat alles mit der Weiterentwicklung der PorscheTypenreihe 356. Das Ziel: Die typische Grundform erhalten und ein Fahrzeug erschaffen, das beste Effizienz mit kompromissloser Fahrdynamik und hoher Alltagstauglichkeit verbindet. Der Boxermotor im Heck, das kompakte Getriebe und ein niedriges Fahrzeuggewicht waren schon damals die Grundbausteine, die dem Porsche 911 bis heute eine außergewöhnliche Traktion und ein grandioses Fahrverhalten garantieren.

Um mit dem 911er bei Sportlichkeit und Sicherheit stets an der Spitze zu bleiben, waren immer neue Fahrwerkstechnologien nötig. So ist im Ur-911er (Modell 901, 1963) die Verwendung einer mechanischen Zahnstangenlenkung, der Verbau von serienmäßig vier Bremsscheiben und der erstmalige Einsatz von unterschiedlichen Reifendimensionen an Vorder- und Hinterachse zu erwähnen. Für den Nachfolger (G-Modell, 1973) wurden für die Hinterachse erstmals Leichtmetallgusslenker entwickelt. Die dritte Generation des 911ers (Modell 964, 1988) war optional mit einem permanenten Allradantrieb zu erhalten. Weiterhin wurden eine hydraulische Zahnstangenlenkung und ein Antiblockiersystem angeboten. Ein großer Schritt bezüglich Bremsperformance wurde mit einem hydraulischen Bremskraftverstärker, innenbelüfteten Bremsscheiben und Leichtmetall-Festsätteln erzielt. Die vierte Generation (Modell 993, 1993) erhielt eine Mehrlenker-Hinterachse mit Spurkorrektur in Abhängigkeit der anliegenden Längs- und Seitenkräfte. Für die fünfte Generation (Modell 996, 1997) sind die Einführung eines elektronischen Stabilitätsprogramms und die erstmalige Verfügbarkeit von Keramikbremsscheiben zu nennen. In der letzten Generation (Modell 997, 2004) sind ein fahrdynamisch orientierter Hang-on-Allradantrieb und semi-aktive Dämpfer zu erwähnen.

In der aktuellen Generation (Modell 991, 2011) wurden verschiedene Fahrwerkregelsysteme zur Spreizung von Fahrdynamik und Komfort eingeführt. Dazu zählen zum Beispiel die elektromechanische Lenkung, die aktive Wankstabilisierung oder das Torque-Vectoring-System.

Mit jeder Modellreihe hat sich der Porsche 911 weiterentwickelt, ohne dabei seinen Charakter oder seine Ursprünglichkeit zu verlieren. Die Agilität und Direktheit des 911 zu spüren, eins zu werden mit der Straße durch die unmittelbare Verbindung zwischen Fahrzeug und Fahrer - dieses Gefühl vermittelt nur ein Porsche 911. Seit nunmehr einem halben Jahrhundert.

Freuen Sie sich - auf viele weitere Jahre mit dem Porsche 911. Und auf die Chassis.tech plus 2013. Auf dieser Tagung hören und erleben Sie noch mehr zum Thema „50 Jahre Porsche 911 die Perfektionierung des Fahrwerks“. Bleiben Sie gespannt! 